\title{
Evaluated the L-spine Magnetic Resonance Imaging for the Scanning Method of the Lateral Recumbent Position with to the Embarrassed Control of the Acute Low Back Pain \\ Jaeheun Lee ${ }^{*}$, Jaeseung Lee ${ }^{*}$, Inchul Im ${ }^{* *}$ \\ Department of Radiology, Pusan National University Hospital ${ }^{*}$, Department of Radiological science, Dongeui University ${ }^{*}$ *
}

\author{
자기공명검사에서 통증제어가 불가능한 급성 요통 환자의 옆으로 \\ 누운 자세에 대한 영상평가$$
\text { 이재흔 }{ }^{*} \text {, 이재승**, 임인철** }
$$ \\ 부산대학교병원 영상의학과 ${ }^{*}$, 동의대학교 방사선학과 * *
}

\begin{abstract}
The acute lumbar pain patients who were unavoidable to take MRI examination were made to take altered lateral recumbent position. they were also not able to control their painfulness and to be in supine position. In this study, it is supposed to increase success rate of the MRI examination through taking the altered lateral recumbent position in using spine and body matrix coil. This altered position made relaxing lumber pain and fatigue for the patients who suffered from sever lumber pain. In these reasons, it decreases the motion artifacts through correcting uncomfortable posture. As a result, qualitative analysis for the image quality was estimated to have average points of supine position A group(lateral recumbent position) of normal candidates and B group(lateral recumbent position) of the abnormal candidates who have sever pain at 4.64, 3.44, and 3.40, respectively. In conclusion, while qualitative analysis in the examination with supine position of the normal patients had significantly high points, the qualitative analysis in the examination with lateral recumbent position of the normal patients and abnormal patients who had sever lumbar pain was almost same. In addition, it was judged that radiologists' imagery interpretation had no other problems in the image evaluation of $\mathrm{B}$ group who had acute lumbar pain of abnormal patients. Hereupon, if this technique becomes generalized for the patients who suffer from supine position in the examination, it is supposed to be useful in medical field.
\end{abstract}

Key Words: Magnetic resonance imaging (MRI), Supine position, Lateral recumbent position, Motion artifact

\section{요 약}

본 연구에서는 통증제어가 거의 불가능한 급성요통 환자를 대상으로 바로 누운 자세를 할 수 없는 환자에게 불가피 하게 자기공명검사를 받아야할 환자를 위해 기존촬영방법인 정상 체위 바로 누운 자세 대신 변형된 옆으로 누운 자세 를 취하게 하여 기존 척추 전용 코일과 복부 전용 코일을 이용하여 요통을 경감시키고 불안정한 자세 보정과 움직임에 
의한 인공물을 줄여 장시간 검사를 받는 환자에게 피로감을 감소시켜 자기공명검사의 성공률을 높이고자 한다. 평가방 법으로는 영상의 질을 정성적 평가로 하였으며 결과로는 정상인 연구대상자 기존촬영방법인 바로 누운 자세의 평균 점 수는 4.64점, 정상인 연구대상자 옆으로 누운 자세(A군)는 3.44점, 극심한 요통을 호소하는 비정상인 연구대상자 옆으 로 누운 자세(B군)는 3.40 점으로 나타났다. 결론적으로 정상인 연구대상자의 기존촬영방법인 바로 누운 자세에서 검 사한 정성적인 평가는 예상대로 높게 나타났으나 정상인 연구대상자 옆으로 누운 자세와 극심한 요통을 호소하는 비정 상인 연구대상자 옆으로 누운 자세로 검사한 영상의 정성적 평가는 거의 비슷하게 나타났다. 또한 극심한 요통을 호소 하는 비정상인 연구대상자 옆으로 누운 자세(B군)의 영상평가에서 영상의학과 전문의의 영상판독에도 문제가 없는 것 으로 나타났다. 이에 바로 누운 자세에서 검사를 진행함에 불편을 겪는 환자에게 이러한 기법이 보편화 된다면 임상에 서 많이 활용될 것으로 사료된다.

중심단어: 자기공명검사, 바로 누운 자세, 옆으로 누운 자세, 움직임 인공물

\section{INTRODUCTION}

요통(low back pain. LBP)이란 허리뼈부의 동통증후 군(myofascial pain syndrome)을 일컫는 말로 직업에 따 른 과도한 노동, 자세에 의한 스트레스, 불규칙적인 건 강상태, 약한 체간 근력 등의 요인에 의해서 유발되며 그 발생률은 1970년 이후 빠르게 증가하고 있는 추세 이다 ${ }^{[1]}$. 요통은 직립보행을 하는 인간에게서 일생동안 $80 \%$ 정도에서 한번은 발생되며 약 $1 \%$ 에서 허리뼈 추 간판 탈출증이 유발되는 것으로 알려져 있으며 근로 자의 $50 \sim 60 \%$ 는 업무 중에도 경험하게 된다 ${ }^{[2],[3]}$. 요통 의 원인은 허리뼈 그 차체에 있는 것보다 허리뼈를 지 지하는 근육 및 인대의 기능 저하와 피로에 의해서 생 기는 경우가 대부분이다 ${ }^{[4]}$. 추간판성 원인(허리뼈 불안 정, 추간판핵 탈출증, 퇴행성 추간판 질환, 척추간 협 착증), 척추골성 원인(발육이상, 척추 분리증, 척추 전 방전위증, 염증, 종양 등), 복부 내 장기에 의한 원인, 신경조직에 의한 원인, 맥관성 원인, 심인성 원인으로 분류하나 ${ }^{[5]}$ 급성 요통의 $80 \%$ 이상이 통증의 원인을 알 수 없고, 여러 가지 요인이 복합적으로 작용하여 치료 계획을 위한 진단에도 어려움이 많이 발생한다. 요통 을 진단하기 위해서는 주로 일반방사선촬영 (general $\mathrm{x}$-ray), 전산화단층촬영(computed tomography. CT), 자기 공명영상(magnetic resonance imaging. MRI) 등이 이용된 다. 관절간부 결손만을 확인하기 위하여서는 전산화단 층촬영이 자기공명검사 보다 우선 되는 검사방법이기 는 하나, 병변 주변의 추간판과 인대, 신경근, 연조직, 척수의 병변을 보기 위해서는 연부 조직 대조도와 분 해능이 높고, 조영제 사용 없이도 조직의 병변부를 양
질로 묘사하는 자기공명검사가 더욱 우수한 영상 검 사법으로 평가 받고 있닽]. 하지만 자기공명검사의 특성상 검사시간(scan time)이 길며 한 자세로 장시간 동안 누워 있어야하는 제한점으로 인해 검사의 성공 률이 타 검사에 비해 낮은 것이 단점이다. 응급실로 내원하는 외상 환자와 급 - 만성의 요통 환자의 경우 검사 전 진통제와 진정제 사용을 병행하여 검사를 진 행한다. 하지만 불안정한 자세와 질환에 의해 움직임 인공물이 동반되며 이로 인해 검사가 실패하는 경우 가 빈번하다. 선행 연구로서 Edelman ${ }^{[7]}$ 은 요통을 호소 하는 환자를 대상으로 국소 부위에 고해상도(high resolution)의 표면 코일(surface coil)을 사용하여 영상을 획득하여 타 검사방법과 비교 평가한 연구 사례도 있 다. 주로 척추 자기공명검사는 바로 누운 자세로 검사 를 하는 것을 원칙으로 하고 있다. 그러나 본 연구에 서는 통증제어가 거의 불가능한 급성요통 환자를 대 상으로 도저히 바로 누운 자세를 할 수 없는 환자에게 서 불가피하게 자기공명검사를 받아야할 환자를 위해 정상 체위인 바로 누운 자세(supine position)대신 변형 된 옆으로 누운 자세(lateral recumbent position)를 취하 고 기존 척추 전용 코일(spine matrix coil)과 복부 전용 코일(body matrix coil)을 이용하여 극심한 요통을 호소 하는 환자를 옆으로 누운 자세를 통해 요통을 경감시 키고 불안정한 자세 보정과 움직임에 의한 인공물을 줄이고 장시간 검사를 받는 환자에게 피로감과 고통 을 감소시켜 자기공명검사의 성공률을 높이고자 한다. 


\section{MATERIAL AND METHOD}

\section{1. 연구 대상}

본 연구는 2013년 07월 01일 부터 2013년 12월 31일 까지 부산 소재 P 대학교 병원을 내원하여 허리뼈부 자기공명검사를 의뢰 받은 환자 중 정상인 연구대상 자 5명과 극심한 요통을 호소하는 비정상인 연구대상 자 5명(남자: 6명, 여자: 4명 평균연령: 56.5⒐15세)을 대상으로 하였으며, 병명으로는 급성 요통환자, 척추 후만증(Kyphosis), 수술 후 감염이 의심되는 환자, 바로 누울 수 없는 환자로 이루어 졌다. 모든 대상자에게 본 연구의 취지를 상세하게 설명한 후 자발적 동의를 얻어 연구를 진행하였으며 폐쇄공포증(claustrophobia) 환자, 심박조율기(pace maker), 치매환자(dementia), 조영 제 부작용 환자는 연구 대상에서 제외 하였으며, 극심 한 요통을 호소하는 연구 대상자의 경우는 담당의와 보호자 동의하에 연구를 진행하였다.

\section{2. 실험 방법}

본 연구에 사용된 자기공명기기는 허리뼈부 자기공 명 검사에 최적화된 $1.5 \mathrm{~T}$ (Magnetom Avanto, Siemens, Germany)를 사용하였으며지 고 신호 강도를 획득하기 위한 척추 전용 위상 배열코일(spine matrix coil)과 복 부 전용 코일(body matrix coil)을 사용하였다. 먼저 정 상인 연구대상자 5 명을 대상으로 기존촬영방법인 바 로 누운 자세에서 검사하기 위해 정자세 위치(true anteroposterior position)로 유지하고 무를 거상 받침대 (elevating knee rest)를 사용(Fig. 1. (a))하여 자세의 편안 함을 유도하여 검사를 하고 이어서 동일한 피험자에 게 옆으로 누운 자세(Group A)로 검사를 재시행 하였 다. 요통을 호소하는 비정상인 연구대상자의 경우는 옆으로 누운 자세(Group B)로만 검사를 하였다(Fig. 1. (b)). 또한 검사 전 연구 대상자의 허리 만곡을 사전에 알기 위해 전산화단층촬영 영상이나 일반촬영 영상의 전·측면 영상을 통해서 허리뼈의 정렬(alignment)과 관 심 부위(region of interest)를 확인하였다. 척추의 장축 이 왜곡되지 않도록 대상자의 허리만곡을 고려하여 옆구리에 스폰지를 넣어 체형을 보상하였으며 무릎과
허벅지 사이에 편안함을 유도 할 수 있게 보조 도구를 사용하였다. 무릎과 팔꿈치를 약간 구부려 안정감을 얻게 하였고 앞가슴 쪽에는 비자장 배게(nonmagnetic pillow)를 사용하여 몸의 균형을 유지하게 했으며 등쪽 에는 복부 전용 코일을 장착 하였다. 또한 환자의 움 직임과 호흡에 의한 코일의 위치 이동을 최소화하기 위해 고정밴드를 사용하였다. 모든 연구대상자에게 Table 1과 같이 동일한 검사 조건과 급속 스핀에코 (turbo spin-echo. TSE)를 사용하여 실험을 진행하였다 [ø. 실험 전 연구대상자에게 검사의 중요성을 설명한 다음 움직임에 의한 영상의 불균형을 최소화 하였으 며 실험에 사용된 세부적인 매개 변수(parameters)는 아 래 표와 같다(Table 1).

Table 1. The modified parameter \& original parameters for the in lumbar spine scan

\begin{tabular}{|c|c|c|c|c|c|c|}
\hline & \multirow{3}{*}{$\begin{array}{l}\text { Original } \\
\text { parameters }\end{array}$} & \multicolumn{5}{|c|}{ Modified parameter } \\
\hline & & \multicolumn{3}{|c|}{$\mathrm{T}_{2}$-TSE } & \multicolumn{2}{|c|}{$\mathrm{T}_{1}-\mathrm{TSE}$} \\
\hline & & Sag & Sag-FS & Axial & Sag & Axial \\
\hline FOV $(\mathrm{mm})$ & 500 & 280 & 280 & 140 & 280 & 140 \\
\hline TR (ms) & 7.8 & 3990 & 3990 & 3000 & 564 & 502 \\
\hline TE (ms) & 3.69 & 134 & 134 & 118 & 9.7 & 12 \\
\hline FA (degree) & 20 & 160 & 160 & 160 & 160 & 160 \\
\hline Thickness (mm) & 6 & 4 & 4 & 4 & 4 & 4 \\
\hline
\end{tabular}
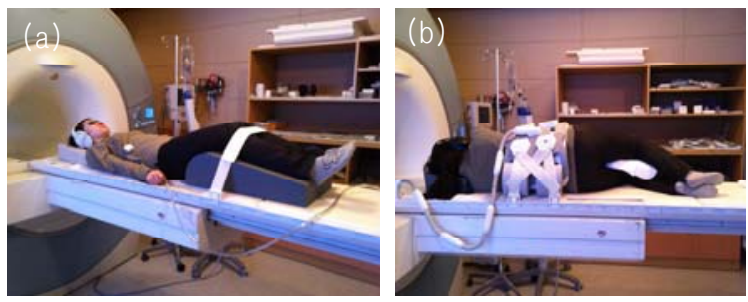

Fig. 1. Setting up the supine position with spine matrix coil(a) and lateral recumbent position with body matrix coil(b). 
"Evaluated the L-spine Magnetic Resonance Imaging for the Scanning Method of the Lateral Recumbent Position with to the Embarrassed Control of the Acute Low Back Pain"
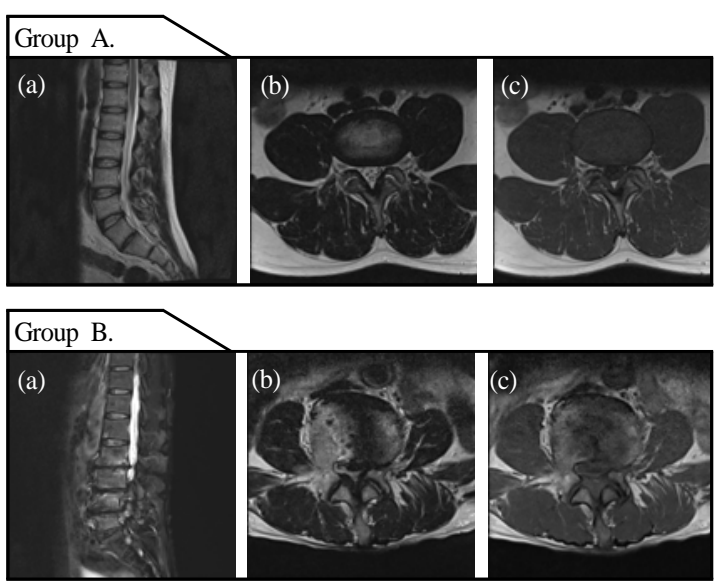

Fig. 2. Group $A$ and $B$ were the MR image from the scan methods of the lateral recumbent positioning in the subjects of normal and acute low back pain, respectively. (a) T2-TSE-Sag, (b) T2-TSE-Axial, and (c) T1-TSE-Axial.

\section{3. 데이터 분석}

영상의 평가와 분석은 연구목적을 설명하지 않은 상태에서 블라인드 테스트(blind test)를 이용하여 근 골격계(musculoskeletal)를 담당하는 영상의학과 전문의 2 명과 전공의 2 명이 영상의 질을 평가하였다. 정상인 연구대상자 5명에 대해 기존촬영방법인 바로 누운 자 세로 얻은 영상은 따로 분류하여 평가하고 정상인 연 구대상자 옆으로 누운 자세에서 얻은 영상을 Group A, 요통을 호소하는 비정상인 연구대상자는 옆으로 누운 자세로 검사한 영상을 Group B로 하여 정성적 분석 (qualitative analysis)을 하였다. 영상의 질에 따라 1점(섬 유륜과 수핵의 구분이 불가능), 2 점(섬유륜과 수핵의 구분이 모호함), 3점(섬유륜과 수핵 구분이 어느 정도 가능하고 추간판과 척추체 종판의 후면경계가 구분이 됨), 4점(척수 신경총과 신경근의 구분이 가능), 5 점(모 든 해부학적 구조물이 명확함)으로 척도화하여 그룹화 된 환자군으로 분석하였다.

\section{RESULT}

연구대상자의 전체적인 영상의 질을 정성적 평가에 의해 살펴보면 다음과 같다(Table 2). 정상인 연구대상 자 기존촬영방법인 바로 누운 자세의 평균 점수는 4.64점, 옆으로 누운 자세의 group $\mathrm{A}$ 는 3.44점, 극심한
요통을 호소하는 비정상인 연구대상자의 옆으로 누운 자세 Group B는 3.40점으로 평가되었다.

Table 2. Results of the qualitative assessment for the state of the patients condition in the scanning method of the supine and the lateral recumbent position.

\begin{tabular}{|c|c|c|c|c|c|c|c|c|}
\hline \multirow{3}{*}{ Group } & & \multirow{3}{*}{ State $^{b}$} & \multirow{3}{*}{ Diagnosis } & \multicolumn{5}{|c|}{ Sequences } \\
\hline & & & & \multicolumn{3}{|c|}{$\mathrm{T}_{2}$-TSE } & \multicolumn{2}{|c|}{$\mathrm{T}_{1}$-TSE } \\
\hline & & & & Sag & Sag-FS & Axial & Sag & Axial \\
\hline \multirow{7}{*}{ Pef. } & 1 & $M$ & $\mathrm{DB}$ & 5 & 4 & 5 & 5 & 5 \\
\hline & 2 & $\mathrm{G}$ & No remarkable & 5 & 4 & 5 & 5 & 4 \\
\hline & 3 & $M$ & Old com. Fx & 4 & 5 & 4 & 4 & 4 \\
\hline & 4 & $G$ & No remarkable & 5 & 4 & 5 & 5 & 5 \\
\hline & 5 & $M$ & No remarkable & 5 & 4 & 5 & 5 & 5 \\
\hline & Avg. & & & 4.8 & 4.2 & 4.8 & 4.8 & 4.6 \\
\hline & $\mathrm{SD}$ & & & 0.0 & 0.4 & 0.4 & 0.0 & 0.5 \\
\hline \multirow{7}{*}{$A$} & 1 & $M$ & DB with $L_{4-5}$ & 4 & 3 & 3 & 4 & 4 \\
\hline & 2 & $G$ & No remarkable & 3 & 3 & 4 & 3 & 4 \\
\hline & 3 & $M$ & $\mathrm{~L}_{1}$ old com. Fx & 3 & 3 & 3 & 3 & 3 \\
\hline & 4 & $\mathrm{G}$ & No remarkable & 3 & 3 & 4 & 4 & 3 \\
\hline & 5 & $M$ & No remarkable & 4 & 4 & 4 & 4 & 3 \\
\hline & Avg. & & & 3.4 & 3.2 & 3.6 & 3.6 & 3.4 \\
\hline & $\mathrm{SD}$ & & & 0.5 & 0.4 & 0.5 & 0.5 & 0.5 \\
\hline \multirow{7}{*}{ B } & 1 & B & \multirow{7}{*}{$\begin{array}{l}\text { BE } \\
F x \text { with } T_{12} \text {, } \\
L_{1-5} \\
F N \text { with } L_{4-5} \\
\text { FS with } L_{4-5} \\
\text { DB with } L_{-4} S_{1}\end{array}$} & 4 & 3 & 3 & 4 & 4 \\
\hline & 2 & $B$ & & 3 & 3 & 4 & 3 & 4 \\
\hline & 3 & $B$ & & 3 & 3 & 3 & 3 & 3 \\
\hline & 4 & $B$ & & 3 & 3 & 4 & 3 & 3 \\
\hline & 5 & B & & 4 & 4 & 4 & 4 & 3 \\
\hline & Avg. & & & 3.4 & 3.2 & 3.6 & 3.4 & 3.4 \\
\hline & $\mathrm{SD}$ & & & 0.5 & 0.4 & 0.5 & 0.5 & 0.5 \\
\hline
\end{tabular}

${ }^{a}$ Ref. was the compared reference scan position (supine) for the comparison results of the qualitative assessment.

${ }^{\mathrm{b}}$ When was the state to the examine patient condition of the magnetic resonance imaging that the ' $\mathrm{M}$ ' moderate, the ' $G$ ' good, and the ' $\mathrm{B}$ ' bad. $D B$ : disc bulging, $F X$. fracture, $B E$ : back edema, $F N$ : foraminal narrowing, FS: foraminal stenosis, $T_{1}-$ and $T_{2}-T S E: T_{1}-$ and $T_{2}$-turbo spin echo, Sag: sagittal, Sag-FS: sagittal-fat suppression.

\section{DISCUSSION}

자기공명영상은 연부 조직의 대조도가 타 검사 방 법에 비교해 뛰어날 뿐만 아니라 수평면(axial plane), 관상면(coronal plane), 시상면(sagittal plane) 등 다방면에 서 영상을 보여줌으로써 골절 이외 모든 척추 및 척수 병변에 가장 진단적 가치가 높은 검사 방법이다 ${ }^{[1]}$. 최 근 급속 스핀 에코 기법(turbo spin-echo. TSE)의 임상 적 사용이 활성화 되면서 기존의 고식적 스핀에코(spin echo. SE)기법보다 영상 획득 시간이 단축 되어 장시간 검사로 인한 검사 실패율이 개선되는 측면도 있다. 척 
추의 자기공명영상을 얻을 때에 가장 문제가 되는 것 은 심박동에 의한 대동맥들의 움직임과 복강 내의 장 기들의 움직임에 의한 움직임 인공물(motion artifact)이 발생 할 수 있다는 점이다. 축상 $\mathrm{T} 1$ 강조 영상 (T1-weighted imaging. T1WI)에서 뇌척수액(cerebrospinal fluid. CSF)의 유입으로 경질막내 공간에서 고신호로 나타날 수 있으며 또한 뇌척수액의 와류로 인하여 T2 강조 영상(T2-weighted imaging. T2WI)에서 저 신호 병 소로 나타날 수 있기 때문에 시상 영상에서 마치 동정 맥 기형(arteriovenous malformation)과 같이 유사하게 나 타난다 ${ }^{[11] .}$ 이런 모든 인공물들이 불안정한 자세를 취 하는 환자나 원인 불명의 요통으로 인해 고통을 호소 하는 대상의 경우에는 복합적으로 움직임 인공물로 나타나 검사의 실패를 가져오거나 판독에 영향을 미 친다. 극심한 요통을 호소하는 환자의 경우에는 바로 누워 있는 것 자체가 힘든 경우가 많으며, 하지 통증 과 동반되어 바로 누운 자세보다 옆으로 누운 자세가 더 고통이 줄어드는 경우가 많다. 본 연구에 참여한 연구대상 중 76세 여성 환자분(Fig. 2. Group B)이 대표 적이라 할 수 있다. 주 진단명은 허리뼈 3 번 척추 분리 증(spondylosis)과 허리뼈 3,4 번 노화와 팽윤(disc bulging and tear), 허리뼈 4,5번은 비대칭 추간공 협착 증(asymmetric foraminal stenosis)과 신경 압박(existing nerve compression)이었다. 이 연구 대상은 산소 포화도 (SPO2)와 심박동수(heart rate)가 기준에 미달되어 진정 제 사용 역시 제한을 받았으며 ${ }^{[12]}$, 바로 누운 자세에 서 진통제의 주입 또한 무의미 하였다. 응급 수술을 계획하는 대상으로 검사를 반드시 진행 해야만 하는 상황으로 정상적인 바로 누운 자세로는 힘든 경우이 지만 옆으로 누운 자세를 유도하고 비강 캐뉼러(nasal cannula)를 통해서 산소를 주입하면서 검사를 하였다. 환자의 협조상태나 누워있기가 힘든 환자인데도 불구 하고 획득된 영상의 정성적 평가 결과 영상의 질은 약 간 저하 되었지만 판독의가 수술을 위한 기본 자료로 서는 문제가 되지 않았다고 하였다. 또한 수술 후 경 과를 지켜봐야 하는 환자의 경우에도 때로는 옆으로 누운 자세 검사가 용이 할 때도 있었으며, 정상적인 자세에서 검사 중 고통을 호소 할 경우 자세를 변형하 여 대상자의 검사 성공률을 높이는 사례도 있었다. 본 연구에서 정상적인 환자군에서는 바로 누운 자세에서
검사한 정성적인 평가는 예상대로 높게 나타났으나 정상적인 환자군 옆으로 누운 자세와 극심한 요통을 호소하는 비정상적인 환자군 옆으로 누운 자세에서 검사한 정성적인 평가는 거의 비슷하게 나타났다. 또 한 통증제어가 불가능한 급성 요통 환자의 옆으로 누 운 자세(Group B)의 영상에서 보여주듯이 허리뼈 질환 의 부위가 잘 나타나고 있다. 그 결과로 영상의학과 전문의의 영상판독에도 별 문제가 없는 것으로 나타 났다. 이에 극심한 요통을 호소하는 환자와 응급을 요 하는 환자, 변형된 척추환자에게는 굳이 약물을 사용 하여 검사하는 것보다 영상판독에 별 문제가 되지 않 는다면 옆으로 누운 자세로 척추 전용 위상 배열코일 과 복부 전용 코일을 사용하여 본 저자가 제시하는 매 개변수로 검사하여 검사시간 단축으로 통증을 최소화 하여 옆으로 누운 자세로 최적의 영상을 만든다면 임 상에서 많이 활용될 것으로 생각된다.

\section{CONCLUSION}

본 연구는 극심한 요통을 호소하는 외상 환자, 응급 환자, 척추변형환자 등 바로 누운 자세에서 검사를 실 패하여 자기공명검사를 중단하기보다는 변형된 옆으 로 누운 자세로 유도하여 검사를 하여도 영상의 질에 따라 정성적 평가 점수가 약간 낮게 나타나는 단점이 있었으나 질환 분별력이나 판독하는데 별 문제가 없 는 것으로 나타났다. 특히 통증제어가 불가능한 요통 을 호소하는 환자들에게 굳이 진정제, 진통제를 사용 하여 검사하는 것보다는 기존의 바로 누운 자세가 안 될 경우 변형된 옆으로 누운 자세로 검사를 하여도 무 관하다는 영상에서 정성적 평가가 입증되었다. 이에 극심한 요통을 호소하는 환자 또는 바로 누운 자세를 할 수 없을 경우 검사의 성공률 역시 높일 수 있다고 판단되며 이러한 기법이 보편화 된다면 임상에서 많 이 활용될 것으로 사료된다.

\section{Acknowledgements}

이 논문은 2014학년도 동의대학교 교내연구비에 의 해 연구되었음.(과제번호 2014AA193) 


\section{Reference}

[1] S. B. Brotzman, E. W. Kevin, "Clinical orthopaedic rehabilitation: an evidence-based approach" 3rd edition, Seoul: Hanmi Medical Publishing Co., pp. 555-559, 2012.

[2] The Korean Orthopaedic Association, "Neurosurgery", 2nd edition, Seoul: Choishineuihaksa, pp. 617-30, 2006.

[3] The Korean Neurosurgical Society, "Neurosurgery", 2nd edition, Seoul: Joongang Publishing Co, pp. 457, 467-468, 2002.

[4] K. W. Lee , "Therapeutic Exercise in Low Back Pain Patients", Journal of Korean Academy of Rehabilitation Medicine, Vol. 19, No. 2, pp. 203-208, 1995.

[5] The Korean Orthopaedic Association, "orthopedics", 6th edition, Seoul: Choishineuihaksa, pp. 449-450, 2006.

[6] J. S. Suh, M.D, "Image Study of the Lumbar Spine", Journal of Korean Spine Surg., Vol. 8, No. 3, pp. 298-304, 2001.

[7] R. R. Edelman, et al, "High-resolution surface-coil imaging of lumbar disk disease", American journal of roentgenology, Vol. 144, No. 6, pp. 1123-1129, 1985.

[8] M. I. Vargas, et al. "Brain and spine MRI artifacts at 3Tesla", neuroradiology, vol. 36, No. 2, pp. 74-81, 2009.

[9] K. M. Jones, R. V. Mulkern, R. B. Schwartz, K. Osgio, P.D. Barnes, F. A. Jolesz, "Fast spin-echo MR imaging of the brain and spine: current concepts", American journal of roentgenology, Vol. 158, No. 6, pp. 131-1320, 1992.

[10] Swain, Andrew, Cromhout, Andre, "Spine and Spinal Cord Injury", ABC of Major Trauma, pp. 246-252, 2013.

[11] Brown, W. Robert, Thompson, R. Michalel, Venkatesan, Ramesh, "Magnetic resonance imaging", New York: Wiley-Liss, 1999.

[12] Jacobi, Judith, et al, "Clinical practice guidelines for the sustained use of sedatives and analgesics in the critically ill adult", Critical care medicine, Vol. 30, No. 1, pp. 119-141, 2002. 